\title{
Linear Viscoelastic and Morphological Description of Multiphase Systems Affected by Processing Parameters
}

\author{
Vanda Kuthanová, ${ }^{1}$ Berenika Hausnerová/ Takeshi Kitano, ${ }^{1}$ Monika Lapč́iková, ${ }^{2}$ Petr Sáha ${ }^{1}$ \\ J.Polymer Centre, Tomas Bata University in Zlin, T. G. M. 275, CZ 762 72, Zlín, Czech Republic institute of \\ Macromolecular Chemistry AS CR, v.v. Z., Heyrovského nám. 2, CZ 162 06, Praha 6-Břevnov, Czech Republic
}

\begin{abstract}
Influence of processing methods, in terms of comparing compression and injection moldings, on the rheological behavior of polycarbonate (PC)/acrylonitrile butadiene-styrene (ABS) blends and PC/ABS/glass fibers composites is presented. Blend compositions and fiber content are considered as material variables. For blends, the effect of the processing route on the viscoelastic functions is evident only for low shearing frequencies. character, while compression molded blends have "relaxed" structure, where dispersed phase domains are several times larger than in injection molded ones. The glass fiber reinforcement led to the significant differences in viscoelastic properties of composites processed by injection and compression molding. Injected composites have both moduli always higher than compression molded, Also, fiber lengths are reduced more for compressing molding.
\end{abstract}

Key words: polymer composites; injection molding; compression molding; morphology; viscoelastic properties

\section{INTRODUCTION}

Majority of polymer mixtures are thermodynamically immiscible, and thus, heterogeneous structure, two glass transition temperatures ${ }^{1}$ (with no shift through compositions $)^{2}$ as well as mechanical and rheological properties below the "log-additivity rule/" are attributes mostly observed. ${ }^{3}$ From industrial point of view, blending is generally considered as mixing process with presence of an appropriate compatibilization method.

Most prevalent methods to achieve compatible blends include addition of a compatibilizer (block or graft copolymer), in situ grafting and/or polymerization by reactive blending. Although these routes are available to improve the compatibility, introducing the third component brings some limitations to practical implementation due to the lack of adequate chemical routes and high expenses. An alternative might be the irradiation treatment as we have shown in our previous papers, ${ }^{4,5}$ or even finding certain concentration, where the blends posses required properties without any treatment. ${ }^{6}$

Polycarbonate (PC) / acrylonitrile-butadienestyrene (ABS) blends are generally considered as immiscible pair. In a compatibilized form, they offer mechanical properties of $\mathrm{PC}$ together with reasonable process- ability and price of ABS. They have been commercially known for some time in automotive industry (interior body panels), office equipment, and appliance housing/-9 Their physical, and consequently, utility properties are governed not only by the features of the individual components (viscosity, molecular weight, molecular weight distribution) and components composition but also by the mixing of components in melt followed by final processing. All mentioned factors affect the blends morphology, which in turn influence blends properties. The results from several authors, which draw the ground of direction for presented PC/ABS blends, are summarized below.

First aspect, effecting thermal, flow, and consequently mechanical properties of $\mathrm{PC} / \mathrm{ABS}$ blends is the presence of low molecular weight (LMW) species, for example, monomers, oligomers, or additives in the commercially produced copolymers. Influence of LMW species contained in SAN or ABS was firstly reported in $1989 .{ }^{10}$ It was proposed that presence of LMW species affects components similarly as a plasticizer, therefore change of viscosity ratios between components can be expected, which in turn 
influences development of blend morphology. Similar result was later confirmed for PC/ABS blends ${ }^{11}$ with the suggestion that LMW species, initially present in the ABS, migrate during melt-mixing toward PC domains. Subtraction of LMW species seems to enhance the chemical affinity between PC and SAN domains at the interface. This in turn decreases the interfacial tension and particles dimensions.

Second aspect is the content of particular components in copolymer. It was observed ${ }^{12}$ that the adhesion between PC and SAN passes a sharp maximum for 25-27 wt \% of acrylonitrile (AN) in copolymer. In the case of PC/ABS, both negative and positive deviations were obtained for 20 and 22 wt \% content of AN.13 It was suggested ${ }^{14}$ that synergistic effect, obtained at certain PC/ABS composition with $22 \mathrm{wt}$ $\%$ of $\mathrm{AN}$, can be broadened by lowering of butadiene (B) content from 29 to $18 \mathrm{wt} \%$. Further, hypothesis of the interlayer zones situated at the interphase boundary was pronounced and confirmed irrespective of the ABS internal composition. ${ }^{15,16}$

Positive deviations from the "log-additivity rule" were observed for ABS-rich blends ${ }^{17}$ from commercially produced components, where $\mathrm{AN}$ and $\mathrm{B}$ contents in ABS were 24 and $16.5 \%, 18$ on the opposite to the reported negative deviations of apparent viscosity for blends containing maleic anhydride-grafted ABS. However, microstructure of the unmodified PC/ABS was coarse and irregular; the microstructure of modified samples (due to reactive blending process) was fine with lamellar morphology oriented along the flow direction of injection molding.

Further, two ABS with AN/B/S contents of 22/ 19/59 and 18-22/32/40-50 were compared, ${ }^{19}$ and positive deviations of tensile strength for the first ABS type were found at 50 and $70 \mathrm{wt} \%$ of PC in the blend, whereas blends containing the second type of ABS showed no positive deviations at all. Partial miscibility over the entire blend composition, even in case that $\mathrm{AN}$ was in as broad range as $23-70 \mathrm{wt} \%$, was reported by Mendelson ${ }^{20}$ for blends of polystyrene-co-acrylonitrile and PC.

Further aspects, which should be taken into account, are conditions of mixing and sample preparation. Conventional twin-screw extruder and injection molding machine were used by Kurauchi and Ohta $^{13}$ to mix and mold, respectively, PC with SAN and two kinds of ABS differing in AN/B ratio. Positive deviations of impact strength at 70 and $90 \mathrm{wt} \%$ of PC were observed for PC/SAN and PC/ABS blends containing 22AN/29B.

Similar treatment, compounding in twin screw extruder with consequent injection molding, was done for 50/50 PC/ABS blend. ${ }^{21}$ Interphase adhesion between $\mathrm{PC}$ and ABS was investigated by testing strength of weldlines. Weldline strength of the blend was dramatically lowered when compared with the pure PC. Although AN content in ABS did not appear to influence the weldline strength, it was improved by increasing rubber content.

In the paper of Guest and Daly,22 PC/SAN blends in the whole composition range underwent treatment analogous to usual processing. Polymers were meltblended using cokneader compounding machine followed by either injection molding (IM) or compression molding $(\mathrm{CM})$. It has been attempted to illustrate investigation of microstructural characteristics via dynamic mechanical properties. Significant differences between the dynamic mechanical properties of IM and CM samples showed IM as a better molding technique resulting in a fine, laminar, oriented structure of IM samples. For compressionmolded samples, a coarse "relaxed" uniform morphology was observed.

In the work of Quintens et al., ${ }^{23}$ shape of relaxation modulus on temperature curve was not typical for an immiscible PC/SAN two phase system, with AN content of $24 \mathrm{wt} \%$, melt mixed similarly. Both transitions seemed to approach each other, thereby shifting from the zones of the pure components and could be interpreted as an evidence of miscibility. On the other hand, the annealed samples $\left(4 \mathrm{MPa}\right.$ at $200^{\circ}$ $\mathrm{C}, 3 \mathrm{~min}$ ) showed two transition regions with plateau in-between, which was interpreted as immiscibility.

McLaughlin ${ }^{24}$ demonstrated the difference resulting from various processing conditions on the dynamic mechanical behavior of PC/SAN blends. Complex modulus and loss tangent of the blends containing 40-80 wt \% of PC in temperature range of $120-160^{\circ} \mathrm{C}$ differed for IM and CM.

Commercially supplied PC and two SAN (content of AN 5.5 and $30 \mathrm{wt} \%$ ) were mixed at twin-screw extruder, and subsequently injection molded. The small shifts of blends $T_{g}$ in comparison to $T_{g}$ of pure components corresponded to a very small miscibility of SAN and PC 25

$\mathrm{PC} / \mathrm{ABS}$ as well as PC/SAN prepared by solution casting and extrusion were studied through the whole composition range by Kim and Burns. ${ }^{26}$ Morphology and $T_{g}$ revealed that phase separation between the PC-rich and SAN-rich phases was more pronounced in the case of PC-rich compositions. Further, compatibility increased more in the regions of SAN-rich composition. From the specific heat increment, it was concluded that SAN dissolved more in PC-rich phase than PC in SAN-rich phase. The extrudate swell passed maximum in the middle of composition range, which was presented as behavior typical of incompatible blends.

The control of the phase structure created during processing is another assumption for successful tailoring of polymer blends, that is, development of materials with desirable performance. ${ }^{27}$ Chaudhry et al. ${ }^{28}$ focused on relationship between processing 
conditions and morphology of 55PC/45ABS (23\% of $\mathrm{AN})$. Compounding was performed on the torque rheometer, under various mixing times, temperatures, and rotor speeds, followed by pressing of samples. Well-defined PC dispersed (PC domains were rather spherically shaped) in ABS phase was obtained for the short times (1 and $2 \mathrm{~min}$ ) or for low temperature $\left(230^{\circ} \mathrm{C}\right)$. Increase of mixing time $(5,7,10$ $\min )$ or temperature $\left(250,270^{\circ} \mathrm{C}\right)$ led to elongation of both the phases and to the formation of "quasi" cocontinuous morphology. In addition, morphology did not alter with mixing speed.

Influence of processing conditions, involving extrusion followed by injection or compression molding, on the microstructure was investigated for PC/SAN blends by McLaughlin. ${ }^{24} \mathrm{CM}$ samples provided spherical dispersion of the minor component; coarse, labyrinth phase cocontinuity of $\mathrm{CM}$ samples was obtained for 50 and $60 \mathrm{wt} \%$ of PC, whereas for IM samples, concentration range of $\mathrm{PC}$ was extended up to $80 \mathrm{wt} \%$.

Morphology gradients through the thickness of injection molded commercial PC/ABS blends were investigated by Hamada et al. ${ }^{29}$ Distribution of PC domains through sample thickness had hyperbolic character with maximum in the center. PC exhibited lamellar structure, which grew larger and became more irregular towards core, and was more oriented in the skin. The same attempt was used to characterize blends at $90 / 10 \mathrm{wt} \% \mathrm{PC} / \mathrm{ABS}$ in. ${ }^{30}$ In the center of the plaque, the morphology appeared as isotropic (in parallel and perpendicular directions) with the ABS phase dispersed in the PC matrix as large $(1 \mid \mathrm{im})$ rubber particles and smaller spherical (0.3 jam) SAN particles. About half the distance from the center to the edge, morphology of free SAN changed from predominantly spherical to mostly string-like. Solitary string-like domains (free SAN) and stringlike domains connected to the large spherical particles (bead-and-string morphology created by ABS), oriented in the injection direction, were observed closer to the edge of samples. The gradient in phase morphology (through the thickness of plaque) was created by the competition between the relaxation rate of the bead-and-string structure and the cooling rate after mold filling. Near the center, relaxation (break up of bead-and-string structure) was proposed to occur due to interfacial-tension-driven break-up and end-pinching mechanisms.

A very comprehensive study through thickness of injection molded PC/ABS blends was done by Lee et al. ${ }^{31}$ Generally, regardless of composition, the blends morphology at the edge and close to that was different from that in the middle part. PC-rich compositions (60-90 wt \%) showed rubber particles (1 pm) connected to SAN strings (bead-and-string structure) oriented in the injection direction at the edges of the samples. With the increase of distance from the edge, SAN strings gradually underwent relaxation-broke up into a series of spherical SAN particles. For that reason, in the center, large rubber particles at higher ABS content interconnected irregularly shaped ABS domains, and smaller free SAN particles were randomly dispersed. Intermediate compositions, that is, 40 and $50 \mathrm{wt} \%$ of PC were characterized by either interconnected bead-andstring structure or stratified sheet-like morphology of ABS at the edge. In the center, the ABS phase appeared to be continuous with irregular elongated holes as well as circular holes created when PC was etched away. The ABS-rich blends had PC domains dispersed in the continuous ABS phase. The PC domains were elongated in the injection direction near the edge, and were spherical in the center of the plaque.

An improvement of the mechanical properties of polymer blends (specially increase of stiffness and strength), in the process of cost-rise absence, might be reached by reinforcement with short fibers. General trend is to use fast, continuous production processes, which mostly involve flow patterns leading to fiber orientation. During the processing, flow fields lead to arrangement of immiscible polymer blends through deformation and orientation of dispersed domains. Although the equilibrium dispersed phase morphology is spherical, shear and elonga- tional flow fields can impart nonequilibrium structure such as dispersed fibrillar domains oriented along flow direction.7,9,32 Rheological properties of these materials are of a key importance during processing.

In this article, viscoelastic properties of injection as well as compression molded PC/ABS blends and their composites with glass fiber in molten state will be measured, and the influence of various factors such as morphology and fiber orientation varying with processing conditions will be discussed.

\section{EXPERIMENTAL}

\section{Materials and sample preparation}

PC Iupilon S3000NF (Mitsubishi Engineering Plastics, Japan) and ABS TFX 170NP (Techno-Polymer, Japan) were used for preparing the polymer blends and composites. The internal composition of ABS evaluated from aH NMR spectra measured in solution reveals 28,13 , and $59 \mathrm{wt} \%$ of acrylonitrile, butadiene, and styrene, respectively.

The ABS contents in the prepared PC/ABS blends were $0,20,40,60,80$, and $100 \mathrm{wt} \%$. Blends are indicated by a two digits number, where the first one indicates the PC content and the second one 


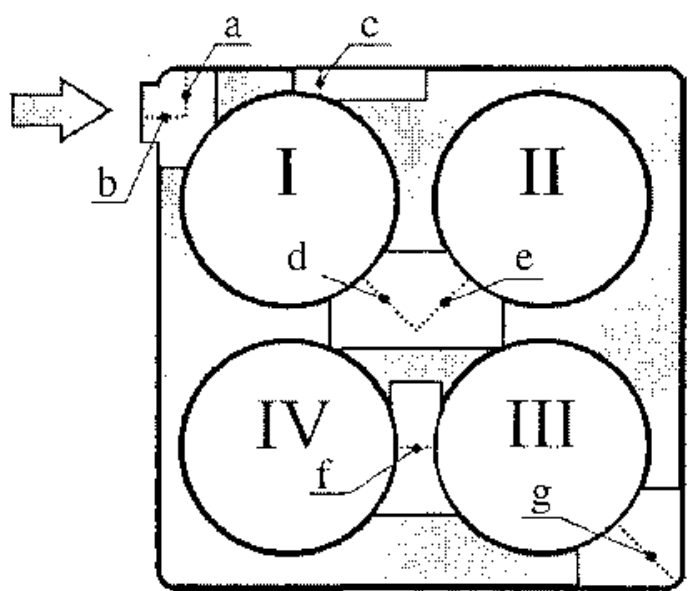

Figure 1 Schematic sketch of positions at IM samples. I- IV are specimens for rheological measurements, a-g denote places investigated with scanning electron microscope; dotted-lines show positions of the cutting surfaces. Arrow is pointing injection gate.

indicates the ABS content, for example, blend containing 20\% PC and $80 \%$ ABS is denoted as blend 28 . PC was dried at $130^{\circ} \mathrm{C}$ and $\mathrm{ABS}$ at $100^{\circ} \mathrm{C}$ for $5 \mathrm{~h}$ before dry-blending, which was followed by meltmixing in a corotational twin screw extruder (TEX 30a, Japan Steel Works, diameter of screw was 32 $\mathrm{mm}$ ) specially designed for fine compounding. The screw speed $90 \mathrm{rpm}$ and temperatures in five zones of $250,250,240,230,220^{\circ} \mathrm{C}$ were set. Extrudates in the form of strings were cut into pellets, and dried at $100^{\circ} \mathrm{C}$ for $5 \mathrm{~h}$ before further processing by either compression molding (CM) or injection molding (IM). In the former case, temperature of $260^{\circ} \mathrm{C}$ and pressure of $9.8 \mathrm{MPa}$ were used. In the latter, injection molding machine J55EL II, JSW with screw diameter of $25 \mathrm{~mm}$ was used for the preparation of testing samples for rheological measurements (shown in Fig. 1). The conditions were as followed: the cylinder temperatures were $260,260,250$ and $240^{\circ} \mathrm{C}$ on the nozzle, front, middle, and rear zones, respectively. The temperature of mold cavity was kept at $80^{\circ} \mathrm{C}$, injection rate of $50 \mathrm{~mm} / \mathrm{s}$ and injection pressure of $138 \mathrm{MPa}$ were used. In both cases, sheets with a thickness of $1 \mathrm{~mm}$ were produced, from which round specimens with a diameter of $25 \mathrm{~mm}$ for rheological measurements were cut.

As shown in our former works, 33,34 blend 64 followed log-additivity rule or exhibited positive deviations for storage and loss moduli irrespective from molecular weight of PC used. This blend was used as a matrix for series of composites prepared by incorporating glass fibers (GF) (diameter of $12 \wedge$ im and initial length of $5 \mathrm{~mm}, 1150 \mathrm{TEX}$, Nihon SheetGlass). Composites referred to as CMP1, CMP2, and CMP3 contained 10, 22.2, and 31.6 wt \% (corresponding to volume contents of $4.3,11.3,17.1 \%$ ) fibers.

\section{Measurements of rheological properties}

Dynamic viscoelastic properties were determined with a rotational rheometer (Rheometric Dynamic Analyzer ARES) using a parallel-plate geometry (plate diameter $25 \mathrm{~mm}$, gap between plates $1 \mathrm{~mm}$ ) equipped with ${ }^{\wedge}$ Orchestrator $^{\mathrm{TM}}$ software. Nitrogen atmosphere was used to eliminate degradation during measurements.

Strain sweep tests at the strain $\left(\mathrm{y}_{0}\right)$ range of 0.01 $100 \%$ for three angular frequencies (GO) $0.1,1$, and 10 $\mathrm{rad} / \mathrm{s}$ were carried out to establish linear viscoelastic region. Test reveals independence of storage and loss moduli on the strains from 0.1 to $4 \%$; strain $1 \%$ was selected as a representative value of linear viscoelastic region.

Measurements were carried out at $240^{\circ} \mathrm{C}$ and at angular frequencies in the range from 0.1 to 100 $\mathrm{rad} / \mathrm{s}$. In the case of compression-molded samples, temperatures 220 and $260^{\circ} \mathrm{C}$ were also considered to calculate the apparent activation energy of the materials.

\section{Fiber content and fiber length distribution in the samples}

The weight contents (<Iy) of GF in the composites were determined gravimetrically after matrix incinerating. Glass fiber volume content $(V f)$ was calculated from the densities of the components. To examine the fiber length distribution, incineration residue was separated into filaments and spread on a glass plate from which photomicrographs were taken. Based on these photomicrographs, the length of approximately 800 filaments was measured, and the number $\left(I_{N}\right)$ and weight $\left(I_{W}\right)$ average fiber lengths in the specimens were computed.

\section{Scanning electron microscopy observation}

The influence of processing methods (compression and injection molding) on the structural arrangement was studied with scanning electron microscopy (SEM) on blends 64 (IM and CM) and 46 (IM).

Specimen surfaces were achieved by cutting the samples with an ultramicrotone (Ultratome ${ }^{\circledR}$ III 8800 , LKB - products AB, Sweden) followed by etching. The etching liquid used was prepared from $0.35 \mathrm{~g}$ of grinded potassium permanganate dissolved in a mixture of $10 \mathrm{~mL}$ of sulfuric acid and $10 \mathrm{~mL}$ of phosphoric acid. Samples were etched for 20 (or 40) s, and then the etching liquid was washed with water for $60 \mathrm{~min}$. 
TABLE I

Composition and Fibers Length Distribution in the Composites Prepared by Injection (IM) and Compression (CM) Molding

\begin{tabular}{|c|c|c|c|c|c|c|c|}
\hline Code & & $\begin{array}{l}\text { Weight fractim } \\
\text { of fibers } \omega_{f}(\%)\end{array}$ & $\begin{array}{l}\text { and Com } \\
\text { Volume fraction } \\
\text { of fiburs } V_{c}(\%)\end{array}$ & $\begin{array}{c}\text { ssion }(\mathrm{CM}) \text { Moldin } \\
\text { Number-average } \\
\text { of fiber length } \\
I_{\mathrm{N}}(\mu \mathrm{m})\end{array}$ & $\begin{array}{l}\text { Whight-average } \\
\text { of fiber length } \\
I_{W}(\mu m)\end{array}$ & $\begin{array}{l}\text { ['olydispersity } \\
\text { index } I_{w} / I_{S}\end{array}$ & $\begin{array}{l}\text { Aspect } \\
\text { ratio }\end{array}$ \\
\hline CMP1 & $\mathrm{JM}$ & 10.0 & 4.7 & 538 & 621 & 1.16 & 448 \\
\hline CMP2 & & 22.2 & 12.3 & 595 & 689 & 1.16 & 49.6 \\
\hline $\mathrm{CMP3}$ & & 31.6 & 17,1 & 475 & 556 & 1,17 & 39.6 \\
\hline CMPL & $C M$ & 10.0 & 4.7 & 478 & 555 & 1.76 & 39.8 \\
\hline $\mathrm{CMP}^{2}$ & & 22.2 & 1.1 .3 & 647 & 514 & 1.15 & 37.2 \\
\hline $\mathrm{CMI}^{3}$ & & 31.6 & 17.1 & 357 & 397 & 1,11 & 29.8 \\
\hline
\end{tabular}

After the above treatment, samples were coated with a thin platinum (Sputter coater BAL-TEC SCD 050) film and examined in a scanning electron microscope Vega TS 5130 (Tescan, Czech Republic).

Cutting surfaces of IM samples from several positions of the sheets were denoted as A, B, C, D, E, F, and $G$. The schematic sketch (Fig. 1) shows the location of these cutting surfaces (A-G) in the sample, and their orientation to the injection gate indicated with a bold arrow. Compression molded sheets were examined at two positions, both placed in the middle of the sheet. The investigated cutting surfaces were perpendicular to each other.

\section{RESULTS AND DISCUSSION}

\section{Fiber content and fiber length distribution}

Although the average fiber lengths $\left(\mathrm{I}_{\mathrm{N}}\right.$ and $\left.I_{w}\right)$ of the CM samples are smaller than IM samples (Table I), crucial factor to compare the two preparation methods is the distribution of fiber lengths (Fig. 2). The distribution of fiber lengths for IM samples is wider than for $\mathrm{CM}$ ones. This trend becomes even more pronounced with the increased fiber content.

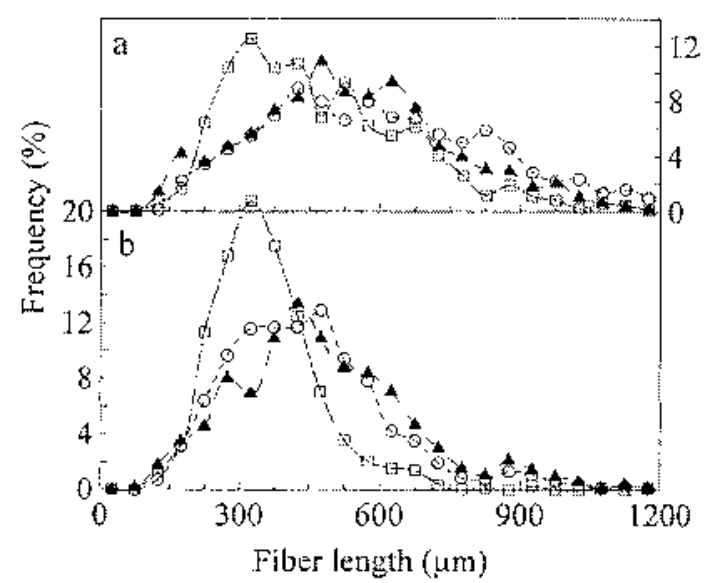

Figure 2 Fiber length distribution of glass fiber filled blend 64 (A CMP1, O CMP2, 口 CMP3) prepared by (a) IM and (b) CM.
During injection molding, the fibers tend to orient in flow direction, and, therefore, the long fibers fraction are not as reduced as during compression molding. Distribution of fiber lengths for CM samples seems to be dependent on the fiber content; it becomes narrower with the increase of fiber content. This tendency is not observed for IM samples.

As reported by Kannan et al., 35 the breakage of fibers occurs mainly during the compounding, followed by a minor consequent reduction during further processing. This is due to the resulting friction as the fibers are introduced to the solid polymer in the extruder, and it is, therefore, presumed that most of the fiber breakage occurs in the melting zone of the extruder. In the mentioned work, ${ }^{35}$ the decrease in $\mathrm{I}_{\mathrm{N}}$ with fiber content was explained by an increase in the frictional forces due to fiber-fiber contact resulting in greater fiber breakage. For PP/ GF composites, 36 it was observed that polydispersity index increased from 1 to 1.7 for $20 \mathrm{wt} \%$ loading, and with rising of shear rate to nearly $10^{4} \mathrm{~s}^{-1}$, it raised to 2 . Breakage of fibers was found to be independent of the die length, occurring mainly in the barrel.

\section{Viscoelastic properties of PC/ABS blends and PC/ABS fiber filled composites}

Viscoelastic properties (storage, G' and loss, G" moduli) of injection molded PC/ABS blends and pure PC and $\mathrm{ABS}$ as a function of angular frequencies are shown in Figure 3 (storage modulus of CM blend 46 is incorporated as well).

Pure PC and blend 82 exhibited, over the whole measured frequency range, higher loss than storage modulus values. This difference in moduli at low angular frequencies is almost one decade, and becomes reduced with increasing co. Blends 64 and 46 at low co reveal higher storage than loss modulus, whereas at high co they behave more viscous. The inflection point is in the first case 0.2 and in the second case $1 \mathrm{rad} / \mathrm{s}$. For the remaining blends and pure ABS, two inflection points were observed. 

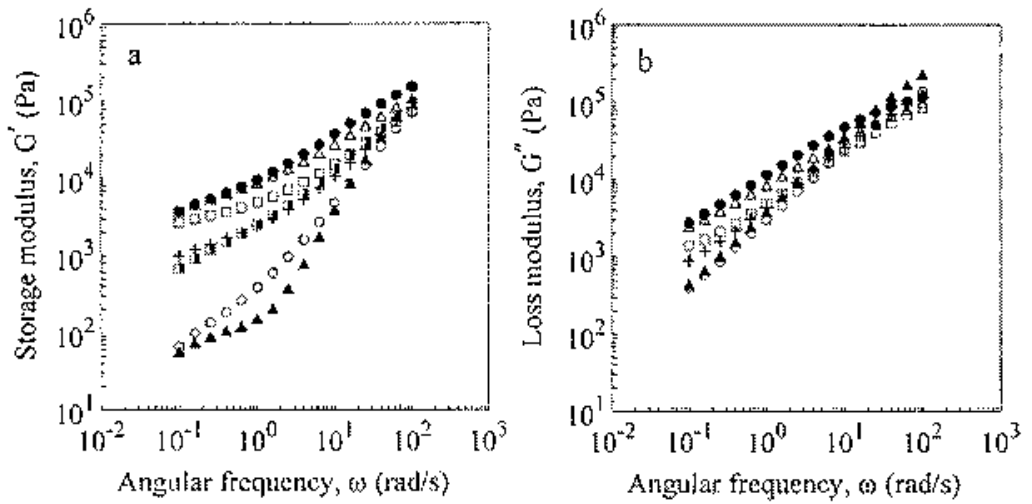

Figure 3 (a) Storage and (b) loss moduli as functions of angular frequency for pure materials (A PC, - ABS) and PC/ ABS blends (O blend 82 , + blend 64, $\square$ blend 46, A blend 28 ) prepared by IM and blend 46 ( $\square$ ) by CM.

The effect of the processing route on $G^{\prime}$ and $G^{\prime \prime}$ is evident only at the low frequency region (Fig. 4), where the structure rising from the processing still remain unchanged upon shearing. Blend 46 seems to be affected the most; its $G^{\prime}$ of $\mathrm{CM}$ (included also in Fig. 3) was found to be $2 / 3$ of decade smaller than $G^{\prime}$ of IM at low angular frequencies.

In most cases (Fig. 4), G' and G" seemed to follow, "log-additivity rule/' The most pronounced positive deviations were observed at 0.1 and $1 \mathrm{rad} / \mathrm{s}$ for the storage modulus of the blends 46 and 64 .

To emphasize the influence of glass fiber content on the viscoelastic properties of composites, the relative storage moduli $G^{\prime}{ }_{r}=G_{\text {composi }}^{\prime} G^{\prime}{ }_{\text {matrix, }}$ and loss moduli, analogously, were calculated. Incorporation of GF influences the viscoelastic properties, specially at the lowest angular frequency $0.1 \mathrm{rad} / \mathrm{s}$ (Fig. 5), where all the composites (CMP1, CMP2, and CMP3) exhibit storage modulus higher than loss. At $1 \mathrm{rad} / \mathrm{s}$, the loss modulus of CMP1 was higher than the storage modulus, whereas values of both moduli of CMP2 and CMP3 were almost equivalent. For angular frequencies of 10 and $100 \mathrm{rad} / \mathrm{s}$, a predominant viscous behavior for all composites was observed, that is, similarly to matrix. Thus, it seems that an increase in angular frequency alters the viscoelastic character of all the composites.

On the opposite to blends (see Fig. 4), composites alter with the way of their preparation significantly.
Both moduli at all measured angular frequencies were for all IM composites higher than for CM composites. The most pronounced differences were detected at the lowest angular frequency $(0.1 \mathrm{rad} / \mathrm{s})$. The reinforcement build-up led to an increase in relative moduli, and further enlarged the differences between IM and $\mathrm{CM}$ samples. These results may be due to the difference of fiber orientation between IM and CM composites as will be shown in the following section.

In Figure 6, the influence of positions on viscoelastic properties in IM samples depicted in Figure 1 is shown. Almost no differences in moduli between positions II and IV were obtained for blend 64 and CMP1, whereas for CMP2, it shows deviations, even more pronounced in case CMP3. Thus, the sample position becomes more important as fiber content increases.
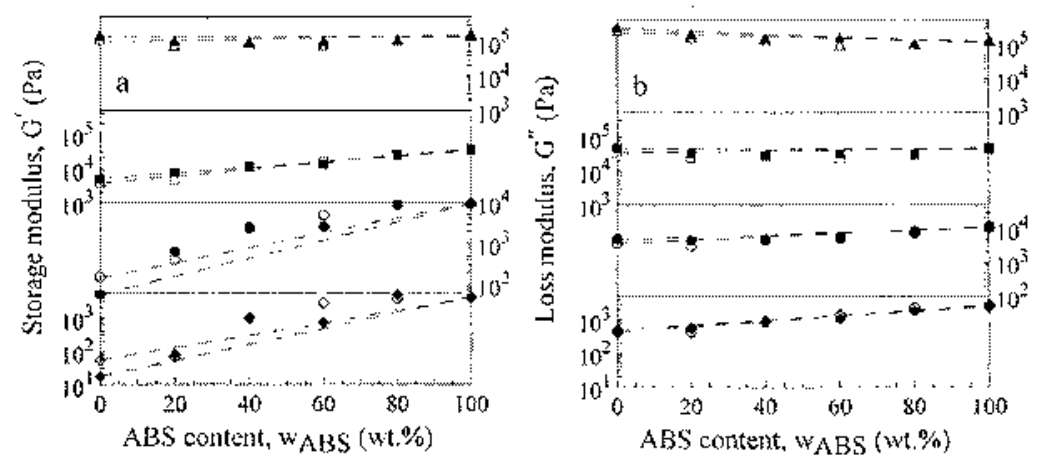

Figure 4 (a) Storage and (b) loss moduli as functions of ABS content for PC/ ABS blends prepared by IM (open symbols) and CM (solid symbols) at various angular frequencies ( $\mathrm{rad} / \mathrm{s}): 0.1(<>\bullet) ; 1(\bullet \mathrm{O}) ; 10(\square \mathbf{u}) ; 100(\mathrm{AA})$ - 

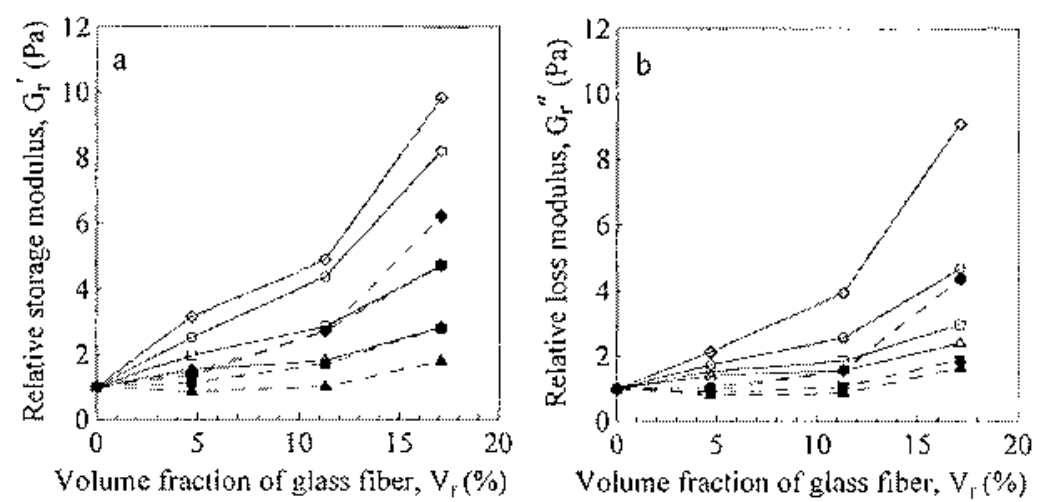

Figure 5 (a) Relative storage and (b) loss moduli as functions of glass fiber content for IM (open symbols) and CM (solid symbols) glass fiber filled blend 64 at various angular frequencies (rad/s): 0.1 (<>४); 1 (®0); 10 (ロ匹); 100 (AA)-

almost unaffected the sensitivity of the matrix,

\section{Temperature dependence of viscoelastic properties}

Storage and loss moduli, measured for compression molded samples at three temperatures $(220,240$, and $\left.260^{\circ} \mathrm{C}\right)$, were plotted versus $1 / \mathrm{T}$, and from the slopes, the apparent activation energies $\left(A_{1}\right.$ for storage and $A_{2}$ for loss modulus) were calculated (Table II).

Our measurements reveal that PC is higher temperature sensitive than ABS. In accordance, the temperature sensitivity of blends decreases with ABS content. Only blends 46 and 64, which are considered as compositions showing the most pronounced positive deviations from log-additivity rule, are exceptions, having almost the same $\mathrm{Aj}$ and $A_{2}$ values. This is in agreement with work by Babbar et al. ${ }^{\mathrm{X}}$ / suggesting that the cause of activation energy might be explained on the basis of miscibility of components in the blend. The ABS-rich blends had better interphase miscibility, and thus were less sensitive to temperature $\left(210-230^{\circ} \mathrm{C}\right)$. On the opposite, Dobrescu et al. ${ }^{\circ}$ reported from capillary measurements in the range of $240-260^{\circ} \mathrm{C}$ that pure $\mathrm{PC}$ is the lowest, pure ABS the intermediate, and the blend containing 60\% of ABS is the highest sensitive to temperature.

From the determined activation energies, the thermal stability of the PC/ABS blends might be viewed. The blends where ABS phase forms the matrix can be assumed as having more stable morphology in comparison to the blends, where matrix is created by PC, which, was found to have the most pronounced temperature sensitivity, and, therefore, their morphology is less stable.

In our work, incorporation of $10 \mathrm{wt} \%$ of glass fiber

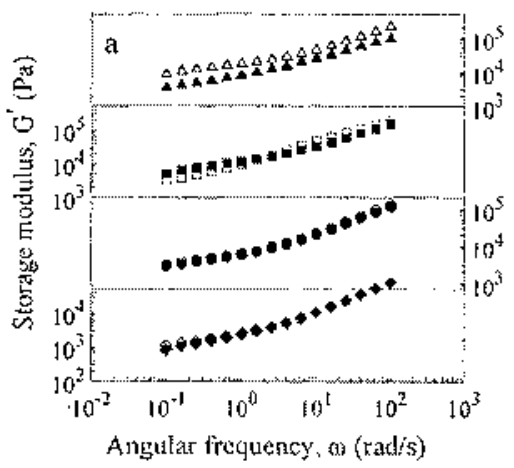

whereas for CMP2 (about 20 wt \%), different behavior was observed. A sudden drop of apparent activation energy (more pronounced at lower angular frequency $0.398 \mathrm{rad} / \mathrm{s}$ ) was detected. In general, loss modulus was found to be more sensitive to temperature changes than storage, contrary to work, ${ }^{38}$ where polypropylene filled with $20 \%$ of glass fiber had the same temperature sensitivity for rj' and $G^{\prime}$.

Figure 6 Comparison of (a) storage and (b) loss moduli at position II (open symbols) and IV (solid symbols) of IM samples for GF filled blend 64 as a function of angular frequency at various GF volume contents (\%): $0(<>\bullet) ; 4.3$ (\#0); 11.3 (口-); 17.1 (AA). 
TABLE II

Apparent Activation Energies of CM Samples Calculated from the Slopes of Storage (Aa) and Loss (A2) Moduli vs. 1/T plots

\begin{tabular}{|c|c|c|c|c|c|c|}
\hline \multirow{2}{*}{$\frac{(1 \mathrm{~kJ}=0.239 \mathrm{kcal})}{\text { Angular frequency }(\mathrm{rad} / \mathrm{s})}$} & \multicolumn{3}{|c|}{ Apparent artivation energy $\left.A_{1}(\mathbf{k} / / m o]\right)$} & \multicolumn{3}{|c|}{ Apparent activation energy $A_{2}(\mathrm{~kJ} / \mathrm{mol})$} \\
\hline & 0.398 & 398 & 39.8 & 0.348 & 3.98 & 39.8 \\
\hline $\mathrm{PC}$ & - & 84.5 & 85.1 & 58.6 & 60.9 & 489 \\
\hline B]end 82 & 28.4 & 52.4 & 59.2 & 47.3 & 49.2 & 41.2 \\
\hline blend 64 & 15.7 & 34.2 & 43.7 & 369 & 34.7 & 32,6 \\
\hline Blend 46 & 19.1 & 34.7 & 44.9 & 36.0 & 41.2 & 353 \\
\hline Bland 28 & 5.7 & 58.8 & 26.9 & 24.8 & 283 & 230 \\
\hline ABS & 4.9 & 16.9 & 18.8 & 20.9 & 19.9 & 9.8 \\
\hline CMP1 & 12.8 & 32.9 & 44.0 & 36.1 & 40.2 & 33.7 \\
\hline $\mathrm{CM}^{2} 2$ & 89 & 26.4 & 39.2 & 31.2 & 37.2 & 33.9 \\
\hline CMF3 & 14.8 & 29.3 & 43.3 & 34.9 & 40.4 & 38.5 \\
\hline
\end{tabular}

\section{Scanning electron microscopy observation}

PC and butadiene were removed by etching leaving acrylonitrile and styrene appearing as brighter regions in the photomicrographs (small dark voids in bright acrylonitrile-styrene regions come from butadiene).

Figure 7 depicts SEM of IM blend 64 in the positions $\mathrm{A}$ and $\mathrm{B}$ close to the injection gate and $\mathrm{D}$ and $\mathrm{E}$ in the middle of the sample. In Figure 7(a), the narrow dimensions of dark particles are seen, whereas in Figure 7(b), their elongated dimensions are observed (cutting surfaces in these pictures are perpendicular to each other). This draw clears the evidence of oriented structure in the flow direction close to the injection gate. SEM demonstrated in the Fig. 7(c,d) with cutting surfaces perpendicular to each other show the particles with similar shape, giving evidence of structure just slightly oriented with flow.

The SEM pictures of two inverse compositions are showed in Figure 8, where in the left column cutting surfaces of blend 64 , and in the right one of blend 46 are placed, demonstrating morphology in the positions C, F, G, and F (see Fig. 1). The phase morphologies of the blends 64 and 46 have very similar cocontinuous character. In the places where-due to a minor influence of flow-the phase separation can occur, dissimilarity of the phase morphologies was detected to a small extent; see Figure 8(c) and (g), where the etched phase (PC) seems to form major and minor phase, respectively.

In case of the compression molded blend 64 (Fig. 9), large irregularly shaped ABS domains are present. In this case, the formation of the PC matrix is clearly evident in comparison to cocontinuous phase morphology of IM samples. Even though the determination of the exact domain size was not calculated, comparison of IM [Fig. 8(d,h)] and CM (Fig. 9) photomicrographs in the same scales gives the clear evidence that the dispersed domains at $\mathrm{CM}$ samples are several times larger than the domains in the IM samples at the investigated positions.

The size and the shape of the dispersed phase domains are varying with the processing method. Moreover, the position in the sample is important in the case of injection moulding samples.

Investigation of morphology through the samples is not included in our work. Nevertheless, skin-core

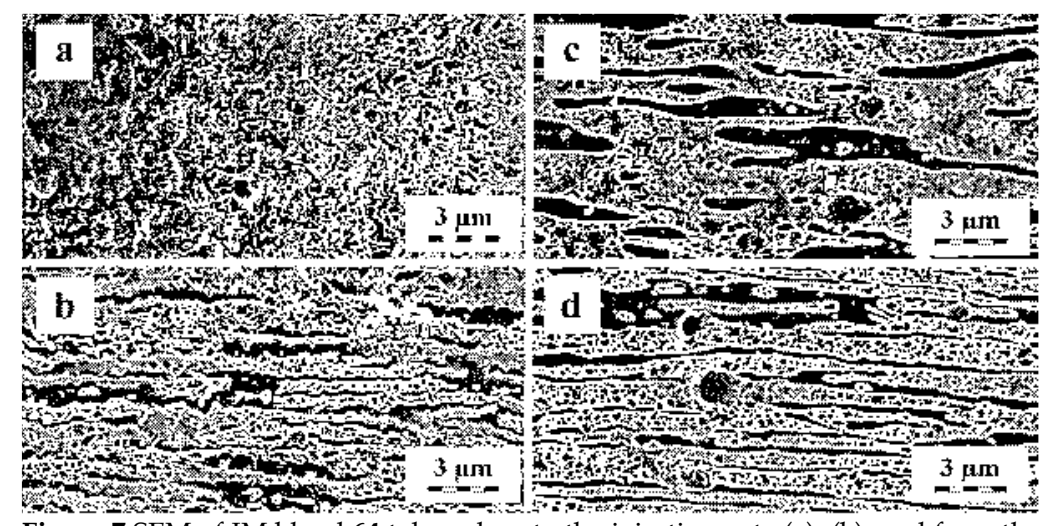

Figure 7 SEM of IM blend 64 taken close to the injection gate $(a),(b)$, and from the middle of the sample (c), (d), corresponding to the positions A, B, D, and E depicted in Figure 1. 


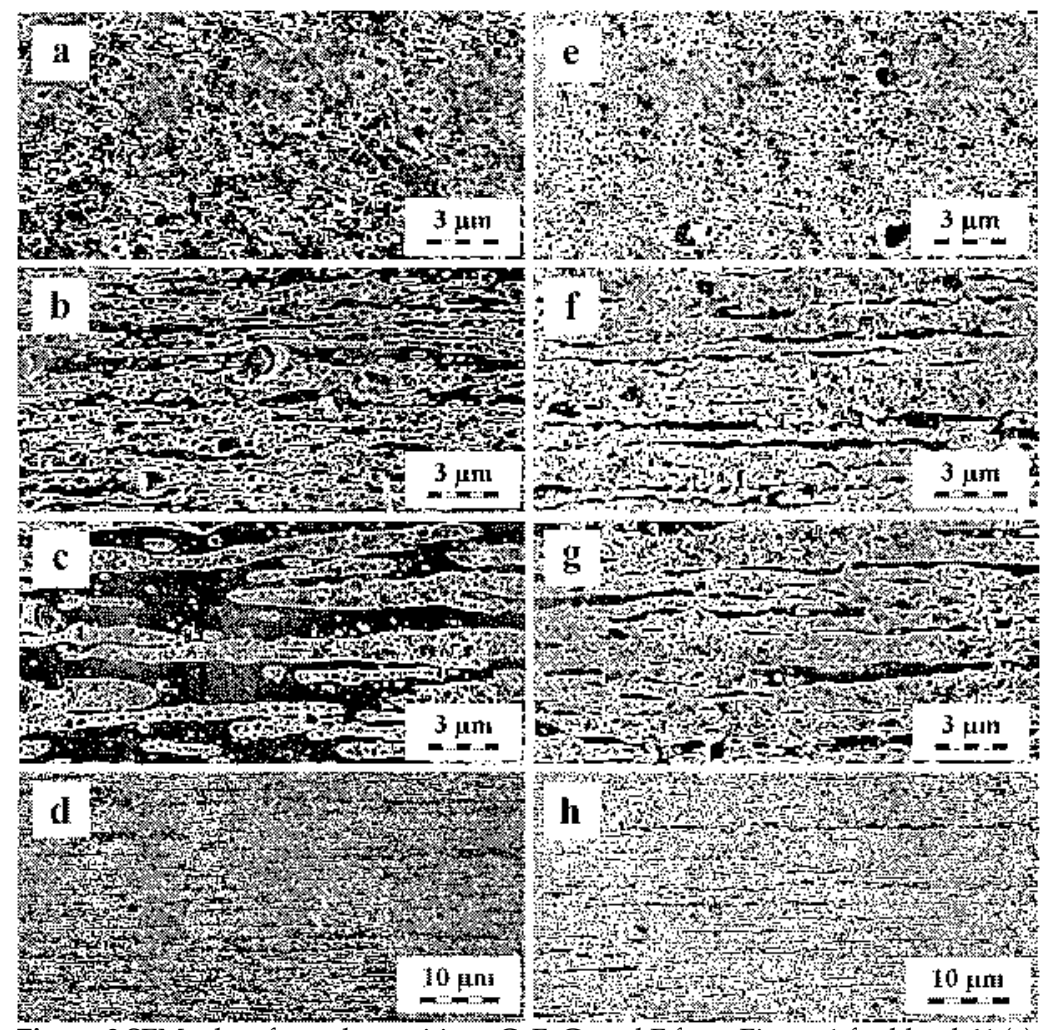

Figure 8 SEM taken from the positions C, F, G, and F from Figure 1 for blend 64 (a), (b), (c), and (d) and blend $46(\mathrm{e}),(\mathrm{f}),(\mathrm{g})$, and (h).

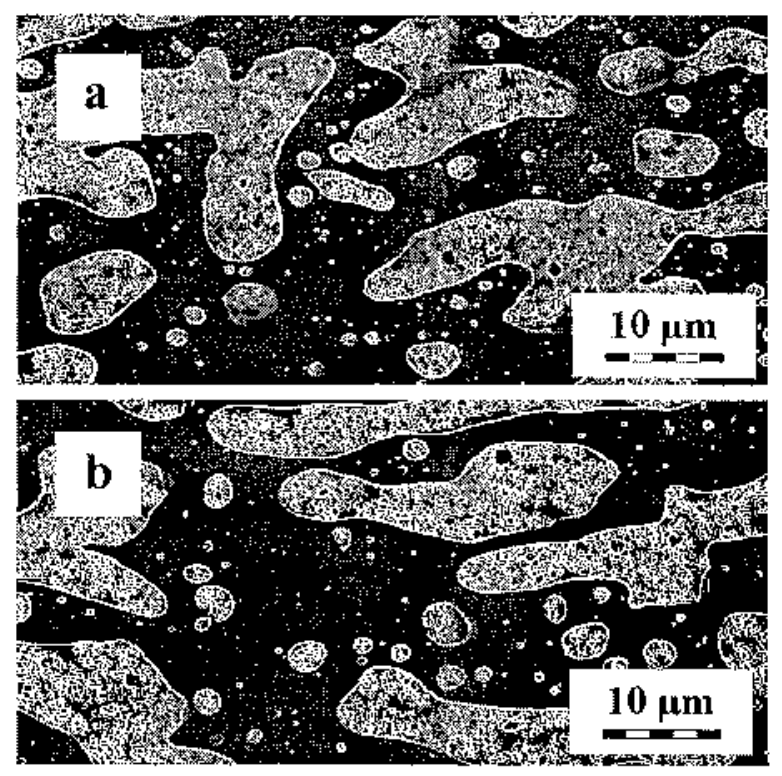

Figure 9 SEM of blend 64 taken from the middle of the CM sample (the cutting surfaces are perpendicular to each another). structure with the highest distribution of PC on the core was reported for IM samples by Hamada and Tsunasawa. ${ }^{39}$ SEM micrographs of the IM and CM samples of the blend 64 with $10 \%$ of glass fiber incorporation are depicted in the Figure 10. Fibers close to the injection gate (a) are rather oriented in the flow direction, whereas fibers located on the positions with minor influence of the flow $(b, c)$ are oriented randomly. It should be stressed that fibers in the IM samples are three dimensionally randomly oriented. The zones close to the injection gate and the narrow layer close to the surface [top of Fig. 10(c)] are exceptions. In case of the CM sample (d), the fibers are more or less oriented in the plane direction.

\section{CONCLUSIONS}

Processing methods of the PC/ABS blends and PC/ ABS/GF composites were compared via rheological and morpological observations. The obtained results can be summarized as follows.

Blends: processing route altered microscopical structure, and only slightly also linear viscoelastic 

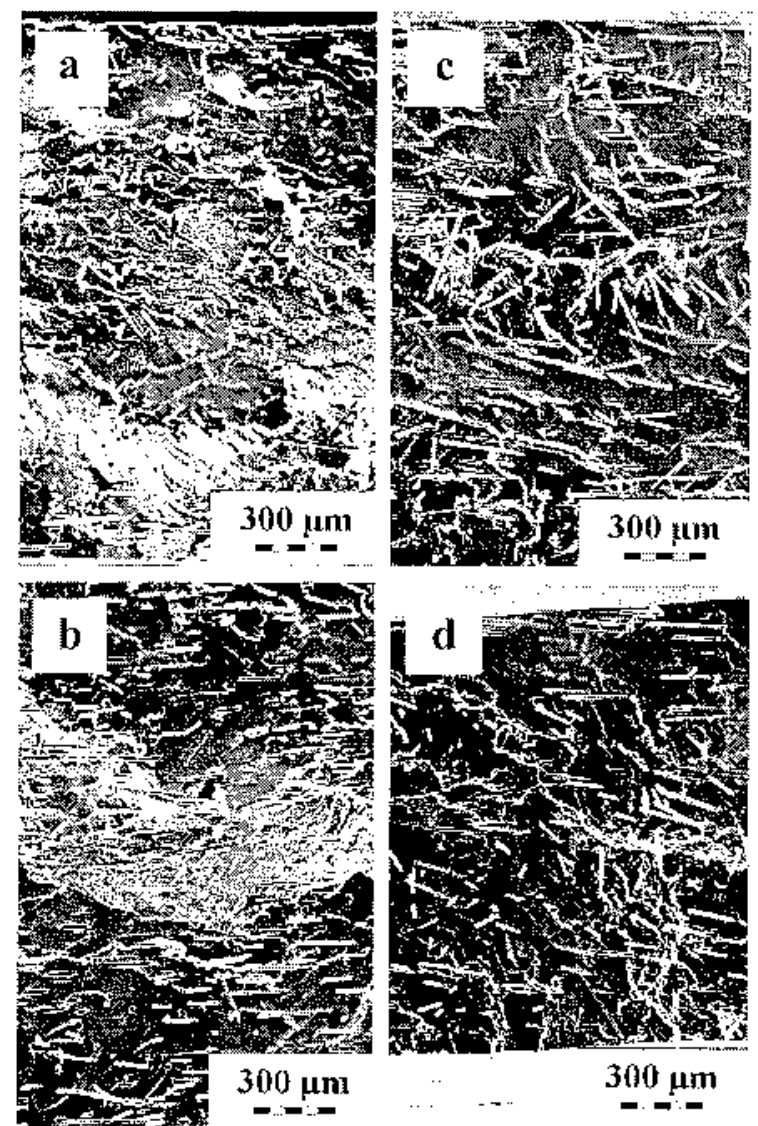

Figure 10 SEM of blend 64 with $10 \%$ of glass fiber taken from the positions $\mathrm{C}, \mathrm{F}$, and $\mathrm{G}$ from Figure 1 for IM samples (a), (b), and (c) and taken from the middle of the CM sample (d).

properties. IM blends seemed to have morphology with appearance of cocontinuous character, whereas CM samples showed "relaxed/' well-defined structure, that is, matrix and dispersed phase were easily distinguished, where dispersed domains were several times larger than in IM samples. Blend 46 was influenced by the processing methods the most. Storage modulus of IM blend 46 was several times higher than $G^{\prime}$ of $C M$ one. Possible explanation comes from dissimilar structural arrangement of IM and CM samples and different contributions of PC and ABS to $G^{\prime}$ of blends. ABS influences elasticity of blends more than PC; Because of the higher homogeneity of IM samples, the impact of ABS character at IM blend is more pronounced. The increase of co causes structure rearrangement leading to decrement of preparation methods influence.

Composites: on the opposite to the blends, the way of composite preparation is important. IM composites have both moduli at all measured angular frequencies higher than $\mathrm{CM}$ ones. Fine, rather heterogeneous structure of IM PC/ABS samples turned into the rather three dimensionally randomly oriented fibers morphology resulting in increase of both moduli of IM samples. The coarse, uniform structure of $\mathrm{CM}$ samples changed into the structure with plane oriented fibers leading to decrease of both moduli. Thus, viscoelastic properties reflect described structures; moduli obtained for the blends reveal $\mathrm{Gi}_{\mathrm{M}}$, $\mathrm{G}^{\wedge}{ }_{\mathrm{M}}<\mathrm{G}^{\wedge}{ }_{\mathrm{M}}, \mathrm{G} £_{\mathrm{M}}$, while for the composites $\mathrm{G}\left\{_{\mathrm{M}}, \mathrm{G}^{{ }^{\prime}}{ }_{\mathrm{M}}>\right.$ $\mathrm{G} \varsigma_{\mathrm{M}}, \mathrm{G} £_{\mathrm{M}}$ were obtained.

The increase of fibber content results in the reduction the fiber lengths. In the $\mathrm{CM}$ composites, the fibers are almost not oriented, which result in the higher breakage of especially long fibers.

Influence of sample position in IM samples was revealed with SEM observations. Close to the injection gate morphology is widely oriented in the direction of flow, whereas close to the center and investigated corner, the orientation was less apparent. These variations of morphology did not influence viscoelastic properties of unfilled systems but fiber-filled systems revealed dependence.

\section{References}

1. Paul, D. R.; Barlow, J. W. J. Macromol Sei Rev Macromol Chem Phys 1980, C18, 109

2. Kulshreshtha, A. K.; Vasile, C. Handbook of Polymer Blends and Composites; Rapra Technology Ltd.: Shrewsbury, 2003.

3. Utracki, L. A. Polymer Alloys and Blends: Thermodynamics and Rheology; Hanser: Munich, 1989.

4. Li, J.; Liang, M.; Guo, S.; Kuthanovä, V.; Hausnerovä, B. J Polym Sei Part B: Polym Phys 2005, 43, 1260.

5. Li, J.; Guo, S.; Slezäk, R.; Hausnerovä, B. Macromol Chem Phys 2005, 206, 2429.

6. Kuthanovä, V.; Honkovä, N.; Hausnerovä, B.; Kitano, T. Nordic Polym Days 2005, 94

7. Bametson, A. Adv in Polymers: Marked and Technical Trends; Rapra Technology Limited: Shrewsbury, 1997.

8. Utracki, L. A. Encyclopeadic Dictionary of Commercial Polymer Blends; ChemTec Publishing: Toronto, 1994.

9. Utracki, L. A. Commercial Polymer Blends; Chapman \& Hall: London, 1998.

10. Guest, M. J.: Daly, J. H. Eur Polym J 1989, 25, 985

11. Greco, R.; Iavarone, M. Polym Eng Sei 2000, 40, 1701.

12. Keitz, J. D.; Barlow, J. W.; Paul, D. R. J Appl Polym Sei 1984, $29,3131$.

13. Kurauchi, T.; Ohta, T. J Mater Sei 1984, 19, 1699

14. Chun, J.-H.; Maeng, K.-S.; Suh, K. S. J Mater Sei 1991, 26, 5347.

15. Greco, R.; Astarita, M. F.; Dong, L.; Sorrentino, A. Adv Polym Technol 1994, 13, 259.

16. Greco, R.; Dong, L. S. Macromol Symp 1994, 78, 141

17. Babbar, I.; Mathur, G. N. Polymer 1994, 35, 2631.

18. Balakrishnan, S.; Neelakantan, N. R.; Saheb, D. N.; Jog, J. P. Polymer 1998, 39, 5765

19. Chiang, W.-Y.; Hwung, D.-S. Polym Eng Sei 1987, 27, 632.

20. Mendelson, R. A. J Polym Sei Polym Phys Ed 1985, 23, 1975.

21. Inberg, J. P. F.; Gaymans, R. J. Polymer 2002, 43, 2425.

22. Guest, M. J.; Daly, J. H. Eur Polym J 1990, 26, 603.

23. Quintens, D.; Groeninckx, G.; Guest, M.; Aerts, L. Polym Eng Sei 1991, 31, 1207.

24. McLaughlin, K. W. Polym Eng Sei 1989, 29, 1560.

25. Skochdopole, R. E.; Finch, C. R.; Marshall, J. Polym Eng Sei 1987, $27,627$. 
26. Kim, W. N.; Burns, C. M. Polym Eng Sei 1988, 28, 1115.

27. Fortelný, I.; Kovář, J.; Stephan, M. J Elastomers Plast 1996, 28,106.

28. Chaudhry, B. I.; Hage, E.; Pessan, L. A. J Appl Polym Sei 1998,

$67,1605$.

29. Hamada, H.; Shonaike, G. O.; Miyaji, S.; Yamane, H. J Mater Sei Lett 1994, 13, 1352.

30. Lee, M.-P.; Hiltner, A.; Baer, E. Polymer 1992, 33, 675.

31. Lee, M.-P.; Hiltner, A.; Baer, E. Polymer 1992, 33, 685.

32. Guell, D. C.; Papathanasiou, T. D. Flow-Induced Alignment in Composite Materials; Woodhead: Cambridge, 1997.

33. Kuthanova, V.; Honkova, N.; Hausnerova, B.; Kitano, T.; Saha, P. Nordic Polym Days 2005, 120.

34. Kuthanova, V.; Hausnerova, B.; Honkova, N.; Kitano, T. Trends in the Development of Machinery and Associated Technology; Goteborg, Sweden, 2006, 265.

35. Kannan, K.; Misra, A. Int Polym Process 1994, 9, 184.

36. Barbosa, S. E.; Kenny, J. M. Polym Eng Sci 2000, 40, 11.

37. Dobrescu, V.; Cobzaru, V. J. Polym Sci Polym Sym 1978, 64,

27.

38. Nishitani, Y.; Sekiguchi, I.; Hausnerova, B.; Nagatsuka, Y.; Kitano, T. Polym Polym Compos 2001, 9, 199.

39. Hamada, H.; Tsunasawa, H. J Soc Mater Sci 1997, 46, 89. 